\title{
Study on the Awareness, Perception, and Willingness to Participate in Covid-19 Vaccine Trials Among Adults in FCT-Abuja, Nigeria
}

\author{
Ekele Peter Ekele ${ }^{1}$, Christie Omolola Adams ${ }^{2 *}$, Osian Eunice Amaechi ${ }^{3}$, Auta Dauda \\ Abimiku $^{2}$, Esther Joseph ${ }^{2}$, Leo Grace Musa ${ }^{4}$, Cishak Paul Bitrus ${ }^{5}$ \\ ${ }^{1}$ International Research Center of Excellence - Institute of Human Virology, Nigeria \\ ${ }^{2}$ University of Abuja Teaching Hospital, Gwagwalada Abuja \\ ${ }^{3}$ Department of Nursing Science, Faculty of Basic Medical Sciences, Benson Idahosa \\ University, Benin City Edo State \\ ${ }^{4}$ Department of Nursing, Health \& Human services Secretariats - Federal Capital \\ Territory Administration (FCTA), Garki-Abuja \\ ${ }^{5}$ Federal Capital Territory (FCT) School of Nursing, Gwagwalada Abuja
}

\begin{abstract}
The Corona Virus Disease 19 (COVID-19) is the greatest threat to public health in recent times. It has infected over 40 million people globally, having an untoward economic impact on many nations. A global race to find a safe and effective vaccine is ongoing, but controversies exist over the conduct of the vaccine trials among the African population. We assessed the awareness, perceptions of, and willingness to participate in the anticipated COVID-19 vaccine trials among adults in the Federal Capital Territory (FCT), Nigeria. Method: We used a web-based cross-sectional correlational survey and a purposive quota sampling technique to select 478 respondents. Results: $65.2 \%$ were aware of the anticipated COVID-19 vaccine trials, $73 \%$ had positive perceptions about it, $63.1 \%$ expressed fear about it, $46 \%$ are not willing to participate in the trials, and $65.2 \%$ will not recommend the trials to a family or friend. The correlation between perception and willingness to participate in the trial was positive and low $(r=0.043, p<0.667)$. Sex, age, religion, Area Councils were significantly associated with willingness to participate in the trials. (P-Values 0.001, 0.003, 0.001 and 0.001 respectively). The primary sources of information about the trials include church/mosque, family, healthcare providers, and friends. Conclusion: There is a high level of Awareness of the COVID-19 vaccine trials; perceptions of the trial are positive, but most people are afraid and will neither participate nor recommend the trials to significant others. We recommend a targeted psychosocial intervention to increase participation in the trial and future COVID-19 vaccine uptake.
\end{abstract}

Keywords: Awareness, COVID-19 vaccine trials, Perception, Willingness.

\section{Introduction}

Coronavirus disease 2019 (COVID-19) is a viral disease caused by a Severe Acute Respiratory Syndrome. Coronavirus 2 (SARS$\mathrm{CoV}-2$ ) was first identified amid an outbreak of respiratory illness cases in Wuhan City, Hubei Province, China. It was initially reported to the WHO on December 31, 2019 [1]. On January 30, 2020, the World Health Organization
(WHO) declared the COVID-19 outbreak a global health emergency. On March 11, 2020, the WHO declared COVID-19 a pandemic. It is the first designation since declaring H1N1 influenza a pandemic in 2009 [2, 3].

Over 40 million persons have been confirmed infected globally, with over 1 million deaths. Africa had 1,262,476 confirmed cases and 24,464 deaths as at 14:00 GMT of $21 / 10 / 2020$ [4]. Nigeria had 61,440 cases with 
1,125 deaths [5]. There have been local, regional, and international efforts to curtail the spread of the virus.

The emerging evidence from China, Europe, and the USA has shown a consistently higher risk of severe COVID-19 in older individuals and those with underlying health conditions [6]. There is a greater risk of severe illness from COVID-19 among vulnerable groups (The elderly, pediatrics, and those with underlying chronic and or acute upper respiratory tract infections). Hence, an individual with severe illness due to COVID-19 will need hospitalization, respiratory support, and the situation may be life-threatening [7].

With this backdrop, vaccine development became imperative to combat the looming extinction of the human race. A COVID-19 vaccine is a biotechnology product intended to provide acquired immunity against coronavirus disease in 2019 (COVID-19). Over 160 vaccines are being developed globally, but about 30 vaccines are already in the human trial phase [8]. As of August 2020, there were 231 vaccine candidates in development, although no candidate had completed clinical trials to prove its safety and efficacy. In August, at least 24 vaccine candidates were announced to be undergoing clinical trials, with six beginning phase III and 18 still in Phase I-II [9].

Previous attempts to develop a vaccine against the coronavirus diseases SARS. Middle East Respiratory Syndrome (MERS) established considerable knowledge about the structure and function of coronaviruses, which accelerated rapid COVID-19 vaccine development during early 2020. Still, all the previous coronavirus vaccine candidates failed in early-stage clinical trials, with none being advanced for licensing [10].

A vaccine for infectious disease has never been produced in less than several years, and no vaccine exists to prevent coronavirus infection in humans [11]. Some vaccines have nonspecific effects beyond the disease they prevent. Two existing vaccines are being tested to determine if either a protective effect against COVID-19 [12].

Assertions have been made that COVID-19 mortality has been lowered in countries having routine BCG vaccine administered against tuberculosis [13]. However, the WHO has said there is no evidence that this vaccine is effective against the COVID-19 virus [14].

A randomized placebo-controlled trial to test whether the measles-mumps-rubella vaccine (MMR) can protect healthcare workers from COVID-19 began with 200 participants during June 2020 in Cairo. There has not been so much promise so far, and we have all started to look beyond this [15].

The rapid development and urgency of producing a vaccine for the COVID-19 pandemic may increase the risks and failure rate of delivering a safe, effective vaccine. Some of the public perceives vaccines as unsafe and unnecessary, thereby abhorring vaccination. This is a global health threat called "vaccine hesitancy," which increases the risk of the further viral spread of COVID-19 [16]

The European Commission organized and held a video conference of world leaders on 4 May 2020, at which US\$8 billion was raised for coronavirus vaccine development [17]. After a vaccine is created, billions of doses will need to be manufactured and distributed worldwide. In April 2020, the Gates Foundation estimated that manufacturing and distribution could cost as much as US\$25 billion [18].

Many experts say that the timeline of twelve to eighteen months stated by U.S. officials for a COVID-19 vaccine is extremely optimistic. Under normal circumstances, during which the stages of vaccine development occur sequentially, a vaccine on average takes eight to fifteen years to get from the laboratory into the hands of health-care providers. The fastest vaccine has ever been developed in five years [19].

Both natural infection and vaccination are facing major hurdles in establishing herd immunity against COVID-19. Artificial small- 
amount pathogen infection (ASAPI) might be a more promising strategy to protect the population from the epidemic. The application of ASAPI in establishing herd immunity is based on the known amount of virus causing only subclinical SARS-CoV-2 virus infection.

The advantages of ASAPI are the following: (1) it requires neither developing a new vaccine nor evaluating the efficacy and side effects of a new vaccine; (2) it does not cause severe disease because the controlled amount of the virus used in ASAPI only causes subclinical virus infection, which is definitely less severe than most natural infections; and (3) the effects of virus antigen changes caused by the virus gene mutation on the immune capacity of ASAPI are minimal compared with those in natural infection and vaccination. The reason for the latter is that the only requirement for ASAPI to match the new antigen is a simple virus processing procedure involving the isolation, identification, amplification, and purification of the newly mutated virus, while this would be much more complicated and difficult in case of natural infection and vaccination and would almost require to the repetition of the entire procedure.

The Russian government has approved a COVID-19 vaccine for widespread use despite it undergoing only a phase I trial (38 people) with no published results. The announcement was made on national television when the president, Vladimir Putin, said, "I know that it works quite effectively, forms strong immunity, and I repeat, it has passed all the needed checks." He claimed that one of his daughters had been given the vaccine. Members of the Russian elite have reportedly also received doses of the vaccine since April. [20, 21].

The chief of the Russian Direct Investment Fund, Kirill Dmitriev, has said that a phase III trial will start in August and will involve thousands of people in Russia, Saudi Arabia, and the United Arab Emirates. The vaccine could then be distributed as early as September 2020.
The approval of a vaccine without largescale testing has caused concern, and researchers have called for the results to be published for scrutiny and for further trials to take place before the vaccine is rolled out to the public [22].

More than 165 SARS-CoV-2 vaccine candidates are currently being assessed around the world, of which eight are undergoing phase III trials, and two have been approved for limited use - the Russian vaccine and a Chinese vaccine. The Chinese government has specially approved the drug company CanSino's Ad5$\mathrm{nCoV}$ vaccine to be used in the armed forces.

Human trials are billed to commence soon in Africa, but there are debates and controversies over the conduct of the trials amongst the African population [23, 24]. The Nigerian government has enlisted five states which include Lagos, FCT, Ogun, Kano, Kaduna, and Sokoto, in the "solidarity trials" being spearheaded by the WHO [25].

There have been myriad of theories and ideologies regarding the origin of COVID-19, with many conspiracy theorists dissuading potential trial participants, especially those of African descent, from partaking in the anticipated vaccine trials and receiving approved vaccines [26]. This portends grave consequences for Nigerians, Africans, and the rest of the world.

A study conducted on Assessment of the Level of Awareness and Knowledge of COVID-19 Pandemic among Syrians showed that the majority of the participants showed generally moderate knowledge about COVID19. Age, education, level of education, and occupation were the only significant factors that improved the level of awareness. Groups of respondents age 35-50 years, college graduates, medical professions, and income over 300,000 Syrian Pounds showed a high level of knowledge and awareness of COVID-19, whereas low income and low education level respondents showed the opposite. Empowering public information regarding the epidemiology 
of the COVID-19 is needed. Medical professional respondents can help educate other groups, and they can communicate with health care providers to control COVID-19 outbreak [27].

Another Study on the awareness, attitude, and practice during the COVID-19 pandemic in Riyadh, Saudi Arabia. Their findings revealed that; of all the participants, $58 \%$ showed a moderate level of awareness, $95 \%$ presented a high attitude, and $81 \%$ presented an adequate practice regarding COVID-19. Significant positive correlation between awareness-attitude $(\mathrm{r}=0.132$, $\mathrm{p}$-value $<0.001)$ and attitudepractice $(\mathrm{r}=0.149, \mathrm{p}$-value $<0.001)$ were found. The gender of the participants was the only common characteristic significantly associated with both awareness and practice. This study revealed that males showed a slight increase $(60 \%)$ in the level of awareness compared to female participants (57\%). However, when it comes to the practice towards COVID-19, females showed slightly better practice $(82 \%)$ than males $(80 \%)$. The World health organization (WHO) and the Ministry of Health $(\mathrm{MOH})$ were the main sources of information. Conclusion: Despite the moderate public awareness, their attitude and practice were better. Therefore, public awareness must be improved to be prepared for epidemic and pandemic situations. A comprehensive public health education program is important to increase awareness and to reach sufficient knowledge [28].

A study to evaluate the willingness to participate in a COVID-19 vaccine trial among Young Adults in China showed that; the majority of participants $(64.01 \%)$ indicated a willingness to participate in COVID-19 vaccine trials. Major concerns included side effects $(69.04 \%)$, concerns from family members $(63.02 \%)$, worries about handicap or death $(58.05 \%)$, and infection through the vaccine (53.03\%). Willingness to participate was associated with demographic variables (females and those from lower social class being more willing), trust in the public health system ( $\mathrm{B}=$ 0.019 [0.002, 0.035]), lower levels of COVID19 stigma $(\mathrm{B}=-0.022[-0.031,-0.013])$, COVID-19 prosocial behaviors $(\mathrm{B}=0.008$ $[0.001,0.015])$, and information sources for COVID-19, including family not being a primary source of information $(\mathrm{B}=-0.144[-$ $0.218,-0.071])$, as well as school $(\mathrm{B}=0.162$ $[0.088,0.236])$ and TV $(B=0.132[0.056$, 0.203]) being primary sources of COVID-19 information. COVID-19 vaccine trial willingness was high overall [26].

In Nigeria, there is a dearth of literature on the awareness, perceptions of, and willingness to partake in the anticipated COVID-19 vaccine clinical trials, a gap which this research seeks to fill.

\section{Methodology}

\section{Study Design and Population}

The study is a cross-sectional correlational survey among adults (persons 18 years and above) residing in the Federal capital territory (FCT) Abuja.

\section{Sample and Sampling}

Sample size of 400 was calculated using Slovin's formula

Given as: $\mathrm{n}=\mathrm{N} /\left(1+\mathrm{N}(\mathrm{e})^{2}\right.$

(C. $\mathrm{I}=95 \%, \mathrm{e}=0.05$ )

Where $\mathrm{n}=$ sample size .

$\mathrm{N}=3,564,100$ (estimated population of FCT).

$\mathrm{E}=0.05$ (margin of error).

But giving a none - response rate of $20 \%$ a sample size of 478 participants was used in this study.

A purposive quota sampling (a nonprobability technique) was used to select 478 participants across the six (6) Area Councils in the FCT. This was based on data from the National Population Commission (2016), which put the population of the FCT at about 3,564,100 people of which Abaji, Abuja Municipal Council, Bwari, Gwagwalada, Kuje, and Kwali Area Councils were estimated to 
constitute $4.2 \%, 55.2 \%, 16.3 \%, 11.3 \%, 6.9 \%$ and $6.1 \%$ of the population respectively. Participants randomly filled in online survey forms across the six (6) Area Council until a specific quota for each Area Council was filled, then data was no longer recorded from the Area Councils.

\section{Eligibility criteria}

\section{Inclusion criteria}

1. Volunteers to participate in the study.

2. Must be age 18 years and above.

3. Must be resident in the Federal Capital Territory.

\section{Exclusion criteria}

1. Decline consent.

2. Less than 18 years of age.

3. Not residing in the FCT.

\section{Method of Data Collection}

A web-based survey questionnaire was designed using the "kobocollect" software tool. The questions were based on study objectives. The form consisted of sections A, B, C, and D used to elicit data on socio-demographic characteristics, awareness of COVID-19 vaccine trials, perceptions of COVID-19 vaccine trials, and willingness to participate in COVID-19 vaccine trials, respectively. The tool was pretested and revised by experienced researchers for appropriateness and completeness. The link to the survey was shared on various social media such as WhatsApp, Facebook, telegram, etc. The survey forms were filled by participants across the six (6) Area Council. However, the response rate was poor, which necessitated the researchers going physically to all the Area Councils to ensure that the respondents fill the online survey as an attempt to complement data collection. Data were recorded for each Area Council until the quota or proportion calculated looking at the FCT-Population Council census for every Area Council was filled.

\section{Ethical Consideration}

Recruitment did not begin until approval was given for the study by the Health Research and Ethics Committee (HREC) of the University of Abuja Teaching Hospital (UATH), Gwagwalada, Abuja. ALL respondents were informed that participation in the study was voluntary and assured that no information provided in the study would be linked to any individual. Participants were informed that they were free to skip any question that makes them uncomfortable or withdraw from the survey altogether at any point they so wish. Options were provided for participants to either "consent to participate" in the survey or "decline," and only participants who clicked on "I consent to participate" had their data recorded.

\section{Method of Data Analysis}

The data collected for this study were analyzed using the Statistical Package for Social Sciences (SPSS) version 20.0. Statistical analysis includes descriptive and inferential statistics. Specifically, frequency and percentages were used to describe the respondent's socio-demographic characteristics and perception of COVID-19 vaccine trials.

For this study a scale was designed to rank perception as positive, neutral/indifferent and negative. The section on perceptions of COVID-19 vaccine trials (i.e., section C) consist of 9 perceptual statements, 6 of which were Negative statements (i.e., questions 1, 2, 3, 4, 6 \& 8) while the remaining 3 were Positive statements (i.e., questions $5,7 \& 9$ ). For Negative statements $\mathrm{SA}=-2, \mathrm{~A}=-1, \mathrm{NA}=0, \mathrm{D}=$ 1, $\mathrm{SD}=2$. For, Positive statements $\mathrm{SA}=2, \mathrm{~A}=1$, $\mathrm{NA}=0, \mathrm{D}=-1, \mathrm{SD}=-2$. The rating scale derived for each participant is indicated as follows;

A cumulative score from +1 to +18 means Positive perception, 0 is Neutral/indifferent perception, while a score from - 1 to - 18 means Negative perception. 
In testing study hypotheses, we used gamma ordinal measure of correlation to assess the correlation between perceptions of COVID-19 vaccine trials and willingness to participate in the COVID-19 vaccine trials (C. I= 95\%, $\alpha=$ $0.05)$ while Chi-square was used to determine the association between willingness to participate in the COVID-19 vaccine trials and socio-demographic characteristics (C. I $=95 \%$, $\alpha=0.05)$.

Data were presented using tables, graphs, and charts.

\section{Results}

Table 1 shows the distribution of the respondents by sex, age, religion, educational qualification, occupation, and Area Council of residence. The information on the table shows that $289(60.5 \%)$ of the respondents are females while $183(38.3 \%)$ are males. Similarly, 141 (29.5\%) of the respondents were between 18 to 27 years, 153 (32\%) were between the age range of 28 - 37 years old, $112(23.4 \%)$ were in the age range of $38-47$ years old, $49(10.3 \%)$ were between the age range of 48 - 57 years old, $23(4.8 \%)$ were between the age range of 58 and above. The table further revealed that $195(40.8 \%)$ of the respondents were Christian, 245 (51.3\%) were Muslim, 35 (7.3\%) belong to African traditional religion, while $3(0.6 \%)$ practice other religions. The result also showed that 25 (99\%) of the respondents had no formal education, $130(27.2 \%)$ had primary education, 114 (23.8) had secondary education, and 209 (43.7\%) had tertiary education. Categorizing the respondents base on occupation, the result depicted that $43(9 \%)$ of the respondents were Artisan, 179 (37.4\%) civil servant, 114 (23.8\%) were private employee, 54 (11.3\%) were students, $67(14 \%)$ were traders, while 21 (4.4\%) of the respondents had other occupation that was not specified. Furthermore, 20 (4.2\%) of the respondents were residing in Abaji, 29 (6.1\%) reside in Kwali, 28 (5.9) reside in Kuje, $46(9 \%)$ in Gwagwalada, $89(18.6 \%)$ lives in Bwari, and 266 (55.6) reside in Abuja Municipal Area council.

Table 1. Socio-Demographic Characteristics of Respondents

\begin{tabular}{|l|l|l|}
\hline Characteristics & Frequency & Percentage \\
\hline Sex & 289 & 60.5 \\
\hline Female & 183 & 38.3 \\
\hline Male & 6 & 1.3 \\
\hline prefer not to say & $\mathbf{4 7 8}$ & $\mathbf{1 0 0}$ \\
\hline Total & 141 & 29.5 \\
\hline Age & 153 & 32 \\
\hline $18-27$ & 112 & 23.4 \\
\hline $28-37$ & 49 & 10.3 \\
\hline $38-47$ & 23 & 4.8 \\
\hline $48-57$ & $\mathbf{4 7 8}$ & $\mathbf{1 0 0}$ \\
\hline 58 and above & \multicolumn{2}{|l|}{} \\
\hline Total & 195 & 40.8 \\
\hline Religion & 245 & 51.3 \\
\hline Christianity & 3 & 0.6 \\
\hline Islam & 35 & 7.3 \\
\hline Other & $\mathbf{4 7 8}$ & $\mathbf{1 0 0}$ \\
\hline Traditional & \\
\hline Total & \multicolumn{2}{|l|}{} \\
\hline Educational Qualification & & \\
\hline & & \\
\hline
\end{tabular}




\begin{tabular}{|l|l|l|}
\hline No Formal Education & 25 & 5.2 \\
\hline Primary & 130 & 27.2 \\
\hline Secondary & 114 & 23.8 \\
\hline Tertiary & 209 & 43.7 \\
\hline Total & $\mathbf{4 7 8}$ & $\mathbf{1 0 0}$ \\
\hline Occupation & 43 & 9 \\
\hline Artisan/handiwork & 179 & 37.4 \\
\hline Civil servant & 114 & 23.8 \\
\hline Private employee & 54 & 11.3 \\
\hline Student & 67 & 14 \\
\hline Trader & 21 & 4.4 \\
\hline Others & $\mathbf{4 7 8}$ & $\mathbf{1 0 0}$ \\
\hline Total & \multicolumn{2}{|l|}{} \\
\hline Area Council & 20 & 4.2 \\
\hline Abaji Area Council & 266 & 55.6 \\
\hline Abuja Muncipal & 89 & 18.6 \\
\hline Bwari Area Council & 46 & 9.6 \\
\hline Gwagwalada Area Council & 28 & 5.9 \\
\hline Kuje Area Council & 29 & 6.1 \\
\hline Kwali Area Council & $\mathbf{4 7 8}$ & $\mathbf{1 0 0}$ \\
\hline Total & vaccine \\
\hline
\end{tabular}

Awareness of the Anticipated COVID-19 Vaccine Clinical Trials among Nigerian Adults

vaccine clinical trial. 312 respondents representing $65.2 \%$ were aware of COVID-19 vaccine clinical trial, $170(31.4 \%)$ were not aware, $16(3.4 \%)$ were not sure.

Table 2 shows respondents' level of awareness of the anticipated COVID-19

Table 2. Are you Aware of the Anticipated COVID-19 Vaccine Clinical Trials?

\begin{tabular}{|l|l|l|l|l|}
\hline & Frequency & Percent & Valid Percent & Cumulative Percent \\
\hline No & 150 & 31.4 & 31.4 & 31.4 \\
\hline Not Sure & 16 & 3.4 & 3.4 & 34.8 \\
\hline Yes & 312 & 65.2 & 65.2 & 100.0 \\
\hline Total & $\mathbf{4 7 8}$ & $\mathbf{1 0 0 . 0}$ & $\mathbf{1 0 0 . 0}$ & \\
\hline
\end{tabular}

\section{Source of Information about COVID-19}

Figure 1 shows respondents' source of information about COVID-19. 201 respondents got their information from either church or mosque, 168 from their family members, 166 got from health care providers, 128 from their friends, 85 got information from television, almost 200 respondents got their information from social media such as facebook, twitter, snapchat, Instagram and other social media platform; while 6 respondents got it through other means which was not specified. 


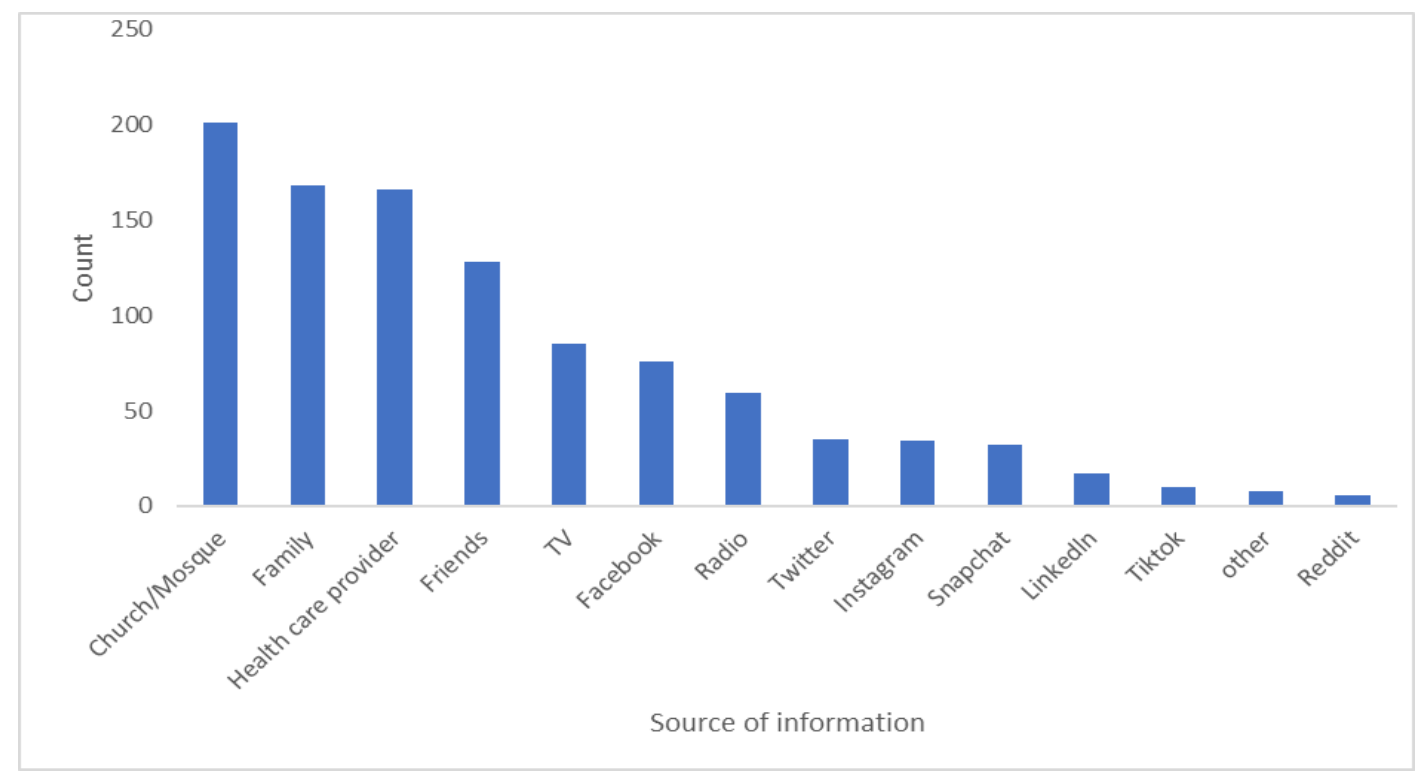

Figure 1. Source of Information

\section{Reaction to COVID-19 Vaccine Trial}

Figure 2 revealed respondents' reactions when they first heard about the COVID-19 vaccine. 58 respondents were interested, 197 respondents were afraid, 52 respondents were indifferent, while 3 respondents had other reactions which were not specified.

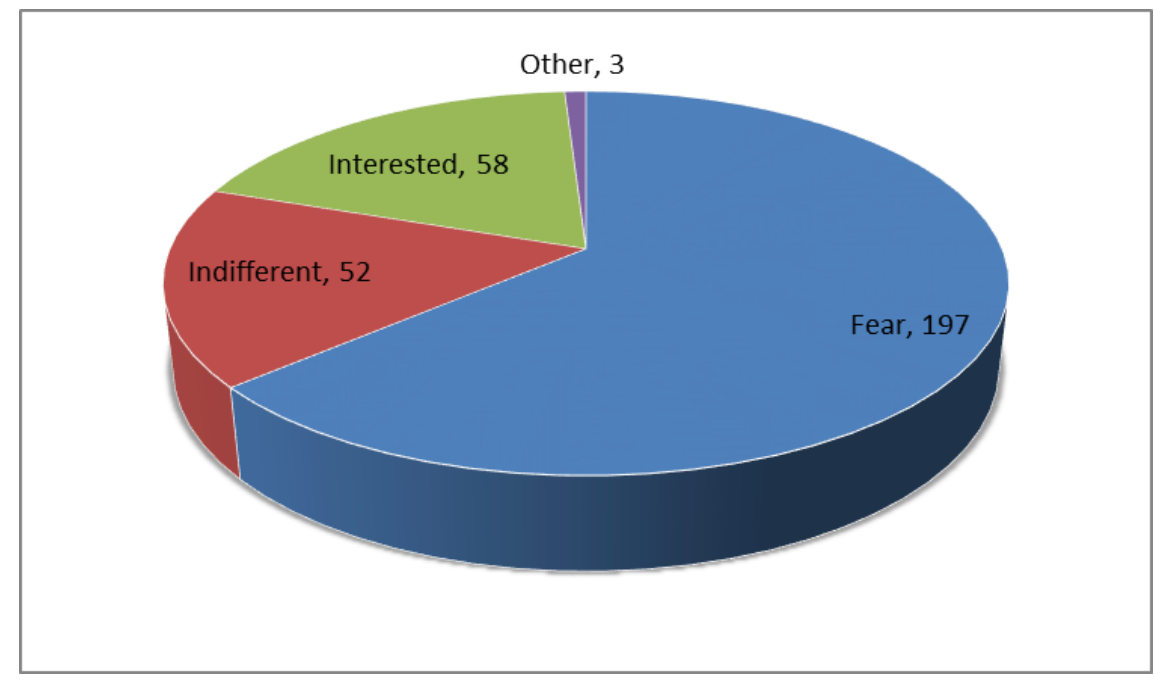

Figure 2. Participants' Reaction to when they First Heard of COVID-19 Vaccine Trials.

Assessment of the Level of Willingness to Participate in the Anticipated COVID-19 Vaccine Clinical Trials among Nigerian Adults

Table 3 display the result on the willingness of respondents to participate in COVID-19 vaccine clinical trial. 28 (9\%) claimed that they were very willing to participate, 53 (17\%) were somewhat willing, 34 (10.9\%) not yet made up their mind about it, 197 (63.1\%) were not willing to participate at all.

Furthermore, Table 4 showed that $9.12 \%$ of the respondents were very willing to recommend their friends for the COVID-19 vaccine trial, $17.1 \%$ were somewhat willing to recommend it to their friends, while $65.1 \%$ were not willing at all to recommend a friend for the vaccine trial. 
Table 3. Are you Willing to Participate in COVID-19 Vaccine Clinical Trials Willingness?

\begin{tabular}{|l|l|l|l|l|}
\hline & Frequency & Percent & Valid Percent & Cumulative Percent \\
\hline Not willing & 197 & 63.1 & 63.1 & 63.1 \\
\hline Not yet made my mind & 34 & 10.9 & 10.9 & 74.0 \\
\hline Somewhat willing & 53 & 17.0 & 17.0 & 91.0 \\
\hline Very willing & 28 & 9.0 & 9.0 & 100.0 \\
\hline Total & $\mathbf{3 1 2}$ & $\mathbf{1 0 0 . 0}$ & $\mathbf{1 0 0 . 0}$ & \\
\hline
\end{tabular}

Table 4. Will you Recommend a Friend or Family Member for the COVID-19 Vaccine Trials?

\begin{tabular}{|l|l|l|l|l|}
\hline & Frequency & Percent & Valid Percent & Cumulative Percent \\
\hline Not willing at all & 200 & 65.15 & 65.15 & 65.15 \\
\hline Not yet made up my mind & 26 & 8.47 & 8.47 & 73.62 \\
\hline Somewhat willing & 53 & 17.26 & 17.26 & 90.88 \\
\hline Very willing & 28 & 9.12 & 9.12 & 100 \\
\hline Total & $\mathbf{3 0 7}$ & $\mathbf{1 0 0 . 0 0}$ & & \\
\hline
\end{tabular}

Assessment of the Perception of the Anticipated COVID-19 Vaccine Clinical Trials among Nigerian Adults

Figure 3 shows respondents' perception of the anticipated COVID-19 vaccine clinical trials among Nigerian Adults. More than 50\% of respondents do not agree with the negative perceptional statements such as "vaccine trial is harmful, it is a way of seeking control of people, it is a way of reducing African population and the vaccine may be a trick from the anti-Christ." Most respondents agreed that clinical trials are necessary for the development of drugs and medical devices. However, most of them opined that there may be serious side effects from the vaccine, participating in the COVID-19 vaccine trial is a high risk, disagreed to the statement "the vaccine will be safe as long as it is approved by appropriate regulatory bodies", and do not believed that the anticipated vaccine could be an effective means of curtailing COVID-19 virus.

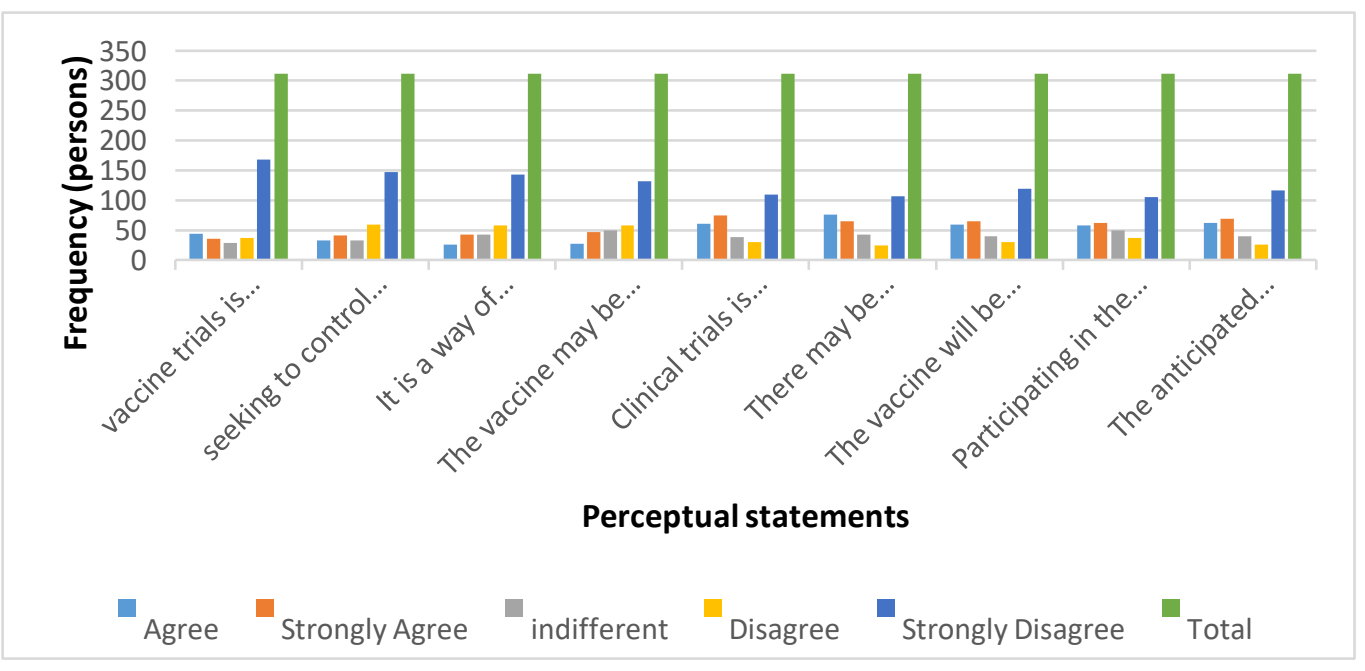

Figure 3. Perceptions of the Anticipated COVID-19 Vaccine Clinical Trials among Nigerian Adults.

Figure 4 shows respondents' overall perception of the anticipated COVID-19 vaccine clinical trials among Nigerian Adults. $73.1 \%$ of the respondents were positive about the vaccine clinical trial, $23.4 \%$ were negative about it, while $3.5 \%$ were indifferent about the vaccine clinical trial. 


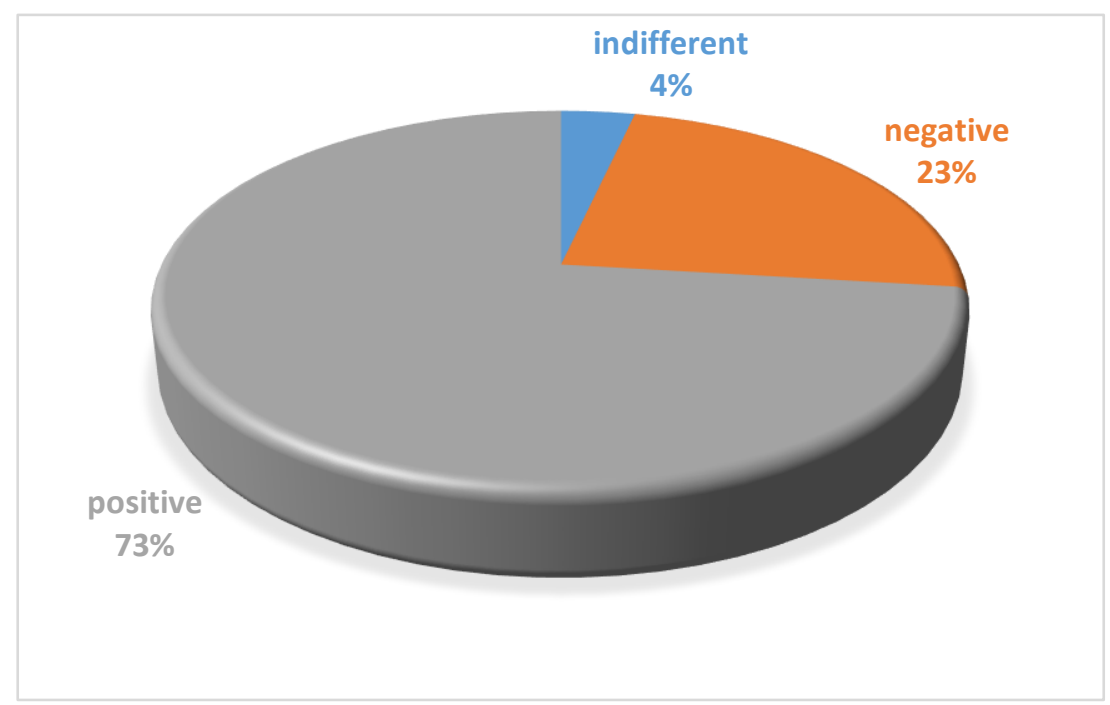

Figure 4: Overall perception of Nigerian Adults on the Anticipated COVID-19 Vaccine Clinical Trial.

Correlation between Perceptions of the Anticipated COVID-19 Vaccine Clinical Trials and Willingness to Participate in Trials among Nigerian Adults

Table 5 showed the correlation between perception and willingness to participate in the anticipated COVID-19 vaccine clinical trials, using gamma ordinal measure of correlation shows the positive and low coefficient of correlation which is $(r=0.043, p<0.667)$, which implies that positive perception does not have strong correlate with willingness to participate.

Table 5. Correlation between Perception and Willingness to Participate in the COVID-19 Vaccine Clinical Trial among Nigerian Adults

\begin{tabular}{|c|c|c|c|c|c|}
\hline \multirow[t]{2}{*}{ Perception } & \multicolumn{4}{|c|}{ Willingness } & \multirow[t]{2}{*}{ Total } \\
\hline & Not willing & NOT yet made-up my mind & Somewhat willing & very willing & \\
\hline Indifferent & 2 & 8 & 1 & 0 & 11 \\
\hline Negative & 51 & 5 & 15 & 2 & 73 \\
\hline Positive & 144 & 21 & 37 & 26 & 228 \\
\hline Total & 197 & 34 & 53 & 28 & 312 \\
\hline \multicolumn{2}{|c|}{ Symmetric Measures } & Value & Asymp. Std. Error ${ }^{a}$ & Approx. $\mathbf{T}^{\mathbf{b}}$ & Approx. Sig. \\
\hline \multirow{2}{*}{$\begin{array}{l}\text { Ordinal by } \\
\text { Ordinal }\end{array}$} & Kendall's tau-b & .021 & .049 & .430 & .667 \\
\hline & Gamma & .043 & .102 & .430 & .667 \\
\hline \multicolumn{2}{|c|}{$\mathrm{N}$ of Valid Cases } & 312 & & & \\
\hline
\end{tabular}

Assessment of Association between Willingness to Participate and Sociodemographic Factors

Table 6 revealed the result of the association between socio-demographic factors and willingness to participate in the COVID-19 vaccine clinical trial. The result indicated that all socio-demographic variables except occupation and education are associated with willingness to participate in the anticipated COVID-19 vaccine clinical trial. More male willing to participate than female, Christian is more willing to participate than Muslim, education does not influence willingness to participate, willingness to participate is low in Abuja municipal. 
Table 6. Socio-demographic Factors and Willingness to Participate

\begin{tabular}{|c|c|c|c|c|c|c|c|}
\hline & Not willing & $\begin{array}{l}\text { Not yet made my } \\
\text { mind }\end{array}$ & $\begin{array}{l}\text { Somewhat } \\
\text { willing }\end{array}$ & Very willing & Total & Chi & p-value \\
\hline \multicolumn{8}{|l|}{ Sex } \\
\hline Female & 131 & 15 & 22 & 9 & 177 & \multirow{4}{*}{26.91} & \multirow{4}{*}{0.001} \\
\hline Male & 64 & 17 & 30 & 19 & 130 & & \\
\hline Prefer-not-to-say & 2 & 2 & 1 & 0 & 5 & & \\
\hline Total & 197 & 34 & 53 & 28 & 312 & & \\
\hline \multicolumn{8}{|l|}{ Age } \\
\hline $18-27$ & 38 & 6 & 13 & 3 & 60 & \multirow[t]{6}{*}{29.99} & \multirow[t]{6}{*}{0.003} \\
\hline $28-37$ & 89 & 9 & 19 & 8 & 125 & & \\
\hline $38-47$ & 51 & 8 & 10 & 7 & 76 & & \\
\hline $48-57$ & 11 & 10 & 9 & 8 & 38 & & \\
\hline 58_and_above & 8 & 1 & 2 & 2 & 13 & & \\
\hline Total & 197 & 34 & 53 & 28 & 312 & & \\
\hline \multicolumn{8}{|l|}{ Religion } \\
\hline Christianity & 71 & 19 & 28 & 21 & 139 & \multirow[t]{4}{*}{21.99} & \multirow[t]{4}{*}{0.001} \\
\hline Islam & 105 & 13 & 24 & 6 & 148 & & \\
\hline Traditional & 21 & 2 & 1 & 1 & 25 & & \\
\hline Total & 197 & 34 & 53 & 28 & 312 & & \\
\hline \multicolumn{8}{|l|}{ Education } \\
\hline $\begin{array}{l}\text { No Formal } \\
\text { Education }\end{array}$ & 6 & 1 & 1 & 2 & 10 & \multirow[t]{5}{*}{15.08} & \multirow[t]{5}{*}{0.089} \\
\hline Primary & 46 & 1 & 7 & 2 & 56 & & \\
\hline Secondary & 48 & 8 & 14 & 6 & 76 & & \\
\hline Tertiary & 97 & 24 & 31 & 18 & 170 & & \\
\hline Total & 197 & 34 & 53 & 28 & 312 & & \\
\hline \multicolumn{8}{|l|}{ Location } \\
\hline Abaji & 3 & 7 & 2 & 2 & 14 & \multirow[t]{7}{*}{148.9} & \multirow[t]{7}{*}{0.001} \\
\hline AMAC & 151 & 12 & 13 & 2 & 178 & & \\
\hline Bwari & 24 & 7 & 25 & 5 & 61 & & \\
\hline Gwagwalada & 6 & 3 & 4 & 10 & 23 & & \\
\hline Kuje & 9 & 3 & 1 & 4 & 17 & & \\
\hline Kwali & 4 & 2 & 8 & 5 & 19 & & \\
\hline Total & 197 & 34 & 53 & 28 & 312 & & \\
\hline \multicolumn{8}{|l|}{ Occupation } \\
\hline Artisan-handiwork & 24 & 1 & 2 & 1 & 28 & \multirow[t]{7}{*}{20.56} & \multirow[t]{7}{*}{0.151} \\
\hline Civil-Servant & 69 & 15 & 24 & 17 & 125 & & \\
\hline Others & 4 & 2 & 4 & 1 & 11 & & \\
\hline Private-Employee & 39 & 8 & 11 & 5 & 63 & & \\
\hline Student & 23 & 4 & 7 & 2 & 36 & & \\
\hline Trader & 38 & 4 & 5 & 2 & 49 & & \\
\hline Total & 197 & 34 & 53 & 28 & 312 & & \\
\hline
\end{tabular}




\section{Discussion}

The findings of this study, as shown in Table 2 revealed that the majority of $61.1 \%$ (292) of the respondents were aware of the anticipated COVID-19 vaccine clinical trial. This could be attributed to the wide scope of awareness campaigns created in the churches and mosques, followed by the viral spread of information on social media platforms. This finding is consistent with the findings from earlier studies, which found a moderate level of awareness of the anticipated COVID-19 [24, 25].

Figures 3 and 4 show the perceptions of the respondents about the anticipated COVID-19 vaccine Figure 4 showed that $73.1 \%$ of the respondents were generally positive about the vaccine clinical trial, while Figure 3 confirms their overall perception as the majority disagreed with common negative statements and axioms of COVID-19 vaccine conspiracy theorists, such as "the vaccine trial is harmful, it's a way of seeking to control peoples mind by introducing microchips into their body, it's a way of reducing African population, and a trick from the anti-Christ." Although their perceptions of the trial were positive, the majority, 197(63.1\%) were not willing to participate, and $200(65.1 \%)$ were not even willing to recommend their friends for the trial. Only $28(9 \%)$ said they are very willing to participate, 53(17\%) were somewhat willing, 34(10.9) not yet made up their mind about it, 197(63.1\%) were not willing to participate at all. These findings are contrary to Sun, Lin, Danhua \& Operario (2020), who conducted a study on Willingness to participate in a COVID-19 Vaccine Trial Among Young Adults in China; the findings showed that; the majority of the participants $(64.01 \%)$ indicated a willingness to participate in COVID-19 vaccine trials. In the current study, COVID-19 vaccine trial willingness was low. This may be attributable to the high level of fear in the participants regarding COVID-19 vaccine trials, as shown in Fig., which reveals that
197(63.1\%) respondents expressed fear about the trials. Also, figure 3 confirms respondents' mistrust in the anticipated trial, as most of them disagreed with the statement that the vaccine will be safe as long as it is regulated by the appropriate bodies. This finding is indicative of an increased level of distrust in the health system and stakeholders involved in the COVID-19 containment. According to the National Cancer Institute NCI (2004), as cited in Williams (2004), fear resulting from mistrust of researchers is a major barrier to participation in clinical trials, hence psychosocial and behavioral interventions in the form of public health Education and campaigns regarding the vaccine may be imperative to facilitate subject recruitment and enrollment into the COVID-19 vaccine clinical trials and to enhance future vaccine uptake when available [31].

Regarding the correlation between perception and willingness to participate in the anticipated COVID-19 vaccine clinical trial, this study showed that there is positive correlation between perception and willingness to participate in the anticipated COVID-19 vaccine clinical trials, however the was the coefficient of correlation is low ( $\mathrm{r}=0.043$, $\mathrm{p}<0.667)$. However, the current study does not corroborate the findings of Hadil, Basingabb, \& Reem (2020), who studied the awareness, attitude, and practice during the COVID-19 pandemic in Riyadh, Saudi Arabia. Their findings revealed that; of all the participants, $58 \%$ showed a moderate level of awareness, 95\% presented a high attitude, and $81 \%$ presented an adequate practice regarding COVID-19. There was significant positive correlation between awareness-attitude $(\mathrm{r}=0.132$, p-value $<0.001)$ and attitude-practice $(\mathrm{r}=0.149$, $\mathrm{p}$-value $<0.001)$.

The assessment of the association between willingness to participate and sociodemographic factors revealed that all sociodemographic variables, except occupation and education, are associated with willingness to participate in the anticipated COVID-19 
vaccine clinical trial. This finding does not corroborate the findings of Hadil, Basingabb, \& Reem (2020) who researched the awareness, attitude, and practice during the COVID-19 pandemic in Riyadh, Saudi Arabia. Their result revealed that the gender of the participants was the only characteristic significantly associated with both awareness and practice [25].

Therefore, public campaigns and awareness by the health workers must be improved during the epidemic and pandemic situations. A comprehensive public health education program is important to increase awareness and to reach sufficient knowledge in outbreaks like this for optimum participation.

\section{Conclusion}

The level of awareness of COVID-19 among Nigerian adults residing in FCT is high. Whereas the respondents have positive perceptions of the trials, they have fears about it and are neither willing to participate in the trials nor willing to recommend it to significant others. The implication of this is an anticipated low subject enrollment in the "solidarity trials" and possible low COVID-19 vaccine uptake when an approved vaccine becomes available.

\section{Recommendation}

We recommend psychosocial and behavioral interventions such as public health campaigns and education involving trusted and respected public figures to increase participation in the trials and future uptake of the approved vaccine.

We suggest further studies as follows:

1. The correlation of exposures to the negative media portrayal of COVID-19 vaccines and the willingness for vaccine trials or uptake.

2. Qualitative studies to explore why Nigerian adults are less willing to participate in COVID-19 vaccine trials.

\section{Limitation of study}

1. This study may be limited by the following factors:

2. Persons who are non-literate or lack access to android phones and the internet may have been excluded from this study.

3. Poor response rate related to reluctance to click on links for fear of Internet fraud or general loss of research interest.

\section{Competing Interest}

There is no competing interest.

\section{Authors Contribution}

1. Conception and/or design of the workEPE, COA.

2. Data collection- All authors.

3. Data analysis and interpretation- EPE.

4. Drafting the article- All authors.

5. Critical revision of the article- All authors.

6. Final approval of the version to be published- All authors. 


\section{References}

[1] David J Cennimo, MD, FAAP, FACP, AAHIVS; Michael Stuart Where did the coronavirus outbreak start? - Medscape.

https://www.medscape.com/answers/2500114197403.

[2] The WHO Just Declared Coronavirus COVID-19 a Pandemic - World Health Organization https://time.com/5791661/who coronavirus pandemic declaration.

[3] 2009 H1N1 Pandemic (H1N1pdm09 virus) CDC - https://www.cdc.gov/flu/pandemicresources/2009-h1n1-pandemic.html.

[4] Dr. Anthony Fauci on COVID-19 Pandemic and Public Health Policy - Director of National Institute of Allergy and Infectious Diseases.

[5] NCDC Coronavirus COVID-19 Microsite https://covid19.ncdc.gov.ng/.

[6] Older Adults and COVID-19 | CDC https://www.cdc.gov/coronavirus/2019-ncov/needextra-precautions/older-adults.html.

[7] Nigerian scientists develop. Covid-19 vaccine need human - Uwagbale Edward-Ekpu https://qz.com/africa/1911951/nigerian-scientistsdevelop-covid-19-vaccine-need-human- trials/.

[8] Coronavirus Vaccine Tracker - The New York Times (2020)

https://www.nytimes.com/interactive/2020/science/c oronavirus-vaccine-tracker.html.

[9] Michael S. Diamond and Theodore C. Pierson (2020) - The Challenges of Vaccine Development against a New Virus during a Pandemic - Cell Host Microbe. 2020 May 13; 27(5): 699-703.2020 May 13. DOI: 10.1016/j.chom.2020.04.021 PMCID: PMC7219397 PMID: 32407708.

[10]COVID-19 vaccine - Wikipediahttps://en.wikipedia.org/wiki/COVID-19_vaccine.

[11] Kleinnijenhuis van Crevel R et al, 2015- Innate Immune Recognition of Mycobacterium https://www.researchgate.net/publication/51156793.

[12] De Vrieze, 2020 - Can a century-old TB vaccine steel the immune system- against-new-coronavirus? https://www.sciencemag.org/news/2020/03/-.

[13] Coronavirus Myth busters - World Health Organization https://www.who.int/emergencies/diseases/novelcoronavirus-2019/advice-for- public/myth busters-. [14] News from the National Library of Medicine 2020 https://www.nlm.nih.gov/news/2020.html.

[15] Thorp, (2020) - COVID-19 vaccine - Wikipedia https://en.wikipedia.org/wiki/COVID-19_vaccine.

[16] Stevis-Gridneff \& Jakes, (2020) - Coronavirus Vaccine Research Gets $\$ 8$ Billion in Pledges https://www.nytimes.com/2020/05/04/world/europe/ eu-coronavirus-vaccine.html.

[17]Blanchfield, (2020) - Blanchfield Army Community Hospital Jobs https://www.indeed.com/q-Blanchfield-ArmyCommunity-Hospital-jobs.html.

[18]Russia registers first COVID-19 vaccine, $\begin{array}{llll}\text { President } & \text { Putin } & 12 & \text { Aug }\end{array}$ https://www.expresspharma.in/covid19updates/russia-registers-first-covid-19-vaccinepresident-putins-daughter-given-a-shot/.

[19]Russian President Vladimir Putin (2020) https://www.cbsnews.com/news/covid-vaccinerussia-coronavirus-development/.

[20] Mahase, (2020) - Covid-19: US approves emergency use of convalescent BMJ 2020; 370 doi: https://doi.org/10.1136/bmj.m3327 (Published 25 August 2020 https://www.bmj.com/content/370/bmj.m3327. [21] Finnan, 2020 - COVID-19 trials at risk after Africa 'racism' backlash - SciDev.Net https://www.scidev.net/global/health/news/covid-19trials-at-risk-after-africa-racism- backlash.html. [22] African Heath Sciences Vol 5 No 3back up.p65 https://www.ajol.info/index.php/ahs/article/view/701 7/1429.

[23] Omeiza Ajayi 12 May 2020. Vanguard Nigeria: COVID-19 - Govt Okays 5 States, FCT for WHO https://allafrica.com/stories/202005120583.html.

[24]Labban L, Thallaj N. \& Labban A. (2020) Assessing the Level of Awareness and Knowledge of COVID-19 Pandemic among Syrians. Archives of Medicine. 12(2) 1-5.

[25] Hadil A., Basingabb F. \& Reem A. (2020) - An analytical study on the awareness, attitude and practice during the COVID-19 pandemic in Riyadh, Saudi Arabia. Journal of Infection and Public Health 13 (2020) 1446-1452. 
[26]Sun, S., Lin, D. \& Operario, D. (2020) Willingness to Participate in a COVID-19 Vaccine Trial Among Young Adults in China. Journal of infectious disease, 221(8) 1-28.

[27] National Population Estimates - National Bureau of Statistics Source: National Population Commission and National Bureau of Statistics Estimates. POPULATION FORECASTS 2006 2016. STATE. 2006. 2007. 2008. 2009. https://nigerianstat.gov.ng/download/474.

[28]Slovin's Formula Sampling Techniques https://sciencing.com/slovins-formula-samplingtechniques-5475547.html.

[29]Louay Labban1, Nasser Thallaj1 and Abear Labban

(Nov.2020)

Assessing_the_Level_of_Awareness_and_Knowled
ge_of_COVID_19_Pandemic_among_Syrians

https://www.researchgate.net/publication/342677705

[30] National Cancer Institute (NCI) | National Institutes of Health (December, 2004) https://www.nih.gov/about-nih/what-we-do/nihalmanac/national-cancer-institute-nci.

[31] Olayinka Victor Ojo, et al. (2020) - Knowledge, Attitude and Willingness of Health Care Workers towards COVID-19 Preventive Measure in a Tertiary Health Institution in North Eastern Part of Nigeria - Central African Journal of Public Health 6(5) DOI: $\quad$ 10.11648/j.cajph.20200605.13 http://article.sciencepublishinggroup.com/pdf/10.11 648.j.cajph.20200605.13. 